\title{
Pembangunan Perangkat Lunak E-Learning dalam Kegiatan Belajar Mengajar Sekolah Menengah Kejuruan Angkasa Husein
}

\author{
Rizky Fauzi Achman ${ }^{1}$, Wina Witanti ${ }^{2}$, Asep Id Hadiana ${ }^{3}$ \\ 1,2,3 Informatika, Universitas Jenderal Achmad Yani
}

\begin{tabular}{l} 
Article Info \\
\hline Article History: \\
Received Jun $12^{\text {th }}, 2021$ \\
Revised Aug $20^{\text {th }}, 2021$ \\
Accepted Aug $31^{\text {th }}, 2021$ \\
\\
Keyword: \\
Kegiatan Belajar Mengajar \\
(KBM), Classroom, E- \\
Learning
\end{tabular}

\begin{abstract}
ABSTRAK
Kegiatan Belajar Mengajar (KBM) dari rumah menggunakan media internet merupakan salah satu proses pendidikan dimana interaksi secara fisik diminimalisir dengan tujuan tertentu. Mengajar atau belajar dari rumah pada saat sekarang menjadi bagian penting dalam kondisi seperti situasi saat ini. Beragam perangkat lunak yang membantu dalam proses Kegiatan Belajar Mengajar (KBM) salah satunya penggunaan perangkat lunak Classroom. Memiliki sisi positif dan juga kelemahan dalam penerapannya, diantaranya terkendala akses internet untuk sebagian orang, fitur - fitur media pembelajaran yang kurang maksimal dan terutama kemampuan aplikasi yang dibangun masih belum "user friendly" atau beberapa fungsi yang belum termanfaatkan secara maksimal, seperti rekapitulasi absensi, penilaian dan pembaharuan materi pada section tertentu. Hal tersebut menjadi tolak ukur untuk membuat pemecahan masalah, meminimalkan kelemahan dengan pengembangan sendiri dalam hal ini dibutuhkan perangkat lunak yang dioptimalkan secara mandiri dengan memanfaatkan E-Learning yang tersedia. Oleh sebab itu perlu pengembangan secara mandiri dengan penggunaanE-Learning, untuk menunjang proses Kegiatan Belajar Mengajar (KBM) di Sekolah Menengah Kejuruan Angkasa Husein Sastranegara Bandung, agar dapat lebih optimal Kegiatan Belajar Mengajar (KBM) tersebut.
\end{abstract}

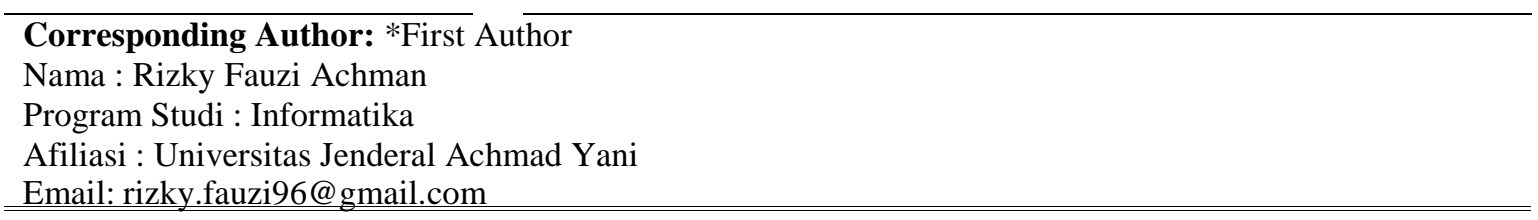

\section{PENDAHULUAN}

Sekolah Angkasa di bawah naungan Yayasan Ardhya Garini memiliki beberapa cabang sekolah yang tersebar di Indonesia diantaranya cabang Lanud Husein Sastranegara Bandung. Pada cabang Husein Sastranegara terdiri dari beberapa tingkat pendidikan dari mulai PAUD, TK, SD, SMP, SMA, SMK. Pada tingkat SMK Angkasa memiliki beberapa masalah dalam proses kegiatan pembelajaran guru mata pelajaran dan siswa diantaranya menganalisis evaluasi hasil belajar siswa, membuat perencanaan ketuntasan materi serta membentuk komunikasi antara guru dan siswa.

Kegiatan Belajar Mengajar (KBM) yang dilakukan memiliki efek positif maupun negatif baik dari sisi sekolah, guru, orangtua, serta siswa dalam teknis pembelajaran. Setiap guru dituntut untuk migrasi ke media teknologi virtual[1]. Berbagai cara dilakukan untuk mengubah media pembelajaran dari mulai dengan menggunakan video conference, pelatihan membuat power point menarik, migrasi menggunakan Classroom[2] dengan proses yang juga perlu beberapa tahapan antara lain buka browser, memasukkan url classroom, tampil login google, memasukkan username dan password sesuai akun google, lalu masuk ke beranda classroom. Penilaian guru kepada siswa dirasa kurang efektif karena dilihat dari proses absensi kehadiran siswa[3], 
pemberian materi melalui media video conference, serta pengerjaan tugas sebagai salah satu komponen pengolahan nilai guru kepada siswa menggunakan Classroom[2].

Dengan latar belakang diatas maka penelitian ini mengambil topik laporan dengan judul

"PEMBANGUNAN PERANGKAT LUNAK E-LEARNING DALAM KEGIATAN BELAJAR MENGAJAR SEKOLAH MENENGAH KEJURUAN ANGKASA HUSEIN”. Diharapkan dengan adanya aplikasi ini dapat lebih mengefektifkan kegiatan belajar dan mengajar yang dilaksanakan dari rumah.

\section{METODE PENELITIAN}

Metode penelitian berisi langkah - langkah yang akan dilakukan dalam Pembangunan Perangkat Lunak ELearning dalam Kegiatan Belajar Mengajar di Sekolah Menengah Kejuruan Angkasa Husein, yang dimulai dari pengumpulan data, pemodelan perangkat lunak, dan dokumentasi.

\section{A. Pengumpulan Data}

Pengumpulan data diperoleh dengan beberapa cara, yaitu :

a. Observasi dengan mendatangi Sekolah untuk mendapatkan informasi tentang proses pembelajaran siswa yang dilakukan. Memahami bagaimana aliran data berjalan sehingga dapat membangun perangkat lunak yang akurat. Observasi dilakukan mulai dari tanggal 23 November 2020 sampai dengan 27 November 2020.

b. Wawancara dengan pihak Sekolah yang menangani perihal berjalannya proses pembelajaran siswa selama Kegiatan Belajar Mengajar (KBM). Narasumber yang dipilih adalah Guru dan Siswa.

\section{B. Pemodelan Perangkat Lunak}

Pada pengembangan dilakukan menggunakan metode Air Terjun (WaterFall) Menurut Rosa dan M. Shalahuddin Model SDLC air terjun (waterfall) sering juga disebut model sekuensial linier (sequential linier) atau alur hidup klasik (classic life cycle). Model air terjun menyediakan pendekatan alur hidup perangkat lunak secara sekuential atau terurut dimulai dari analisis kebutuhan perangkat lunak, desain, pembuatan kode program, pengujian, dan pemeliharaan (maintenance) [4]. Tahapantahapan dari model waterfall diuraikan pada Gambar 1.

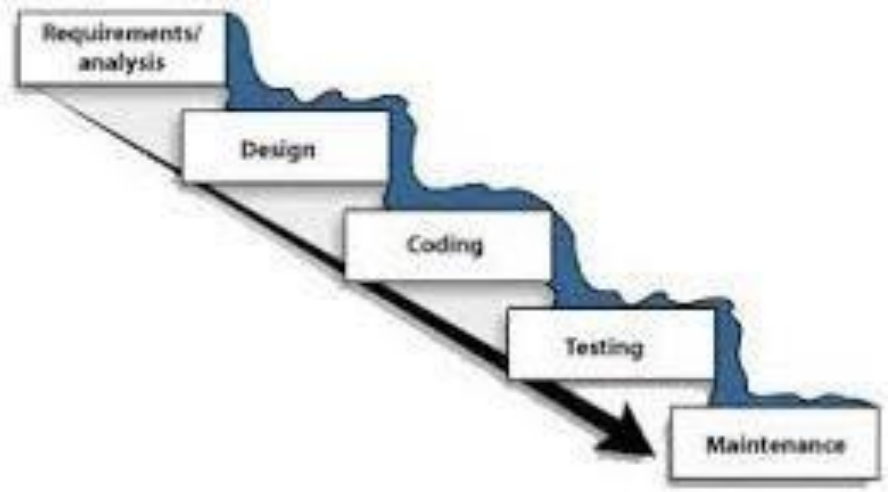

Gambar 1. Model Proses Waterfall

a. Analisis Kebutuhan Perangkat Lunak

Melalui proses observasi dan wawancara yang dilakukan secara intensif untuk menspesifikasikan kebutuhan perangkat lunak agar dapat dipahami perangkat lunak seperti apa yang dibutuhkan oleh user. Spesifikasi kebutuhan perangkat lunak pada tahap ini perlu untuk didokumentasikan.

b. Desain

Desain perangkat lunak adalah proses multi langkah yang fokus pada desain pembuatan program perangkat lunak termasuk struktur data, arsitektur perangkat lunak, representasi antarmuka, dan prosedur pengkodean. Tahap ini mentrannslasi kebutuhan perangkat lunak dari tahap analisis kebutuhan ke representasi desain agar dapat diimplementasikan menjadi 
program pada tahap selanjutnya. Desain perangkat lunak yang dihasilkan pada tahap ini juga perlu didokumentasikan. Gambaran umum sistem yang dibentuk diuraikan pada Gambar 2.

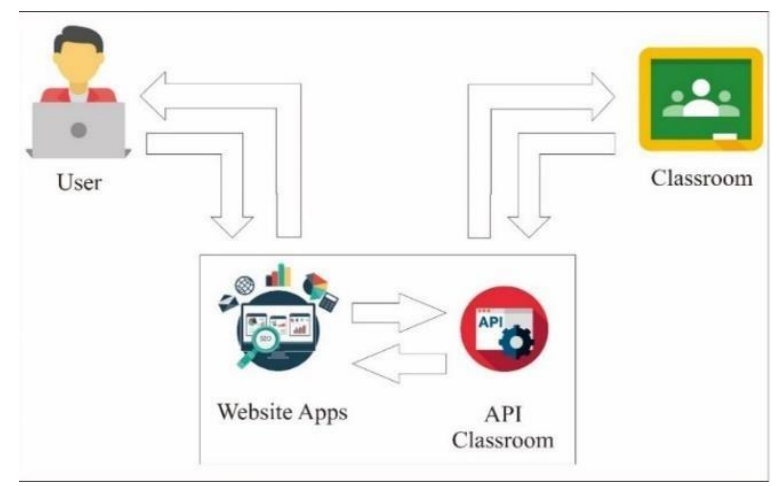

Gambar 2. Gambaran Umum Sistem

- Input

Data masukan yang dibutuhkan dalam perangkat lunak pada Sekolah Menegah Kejuruan Angkasa Husein Sastranegara Bandung berupa data akun email guru dan siswa, data mata pelajaran, data materi mata pelajaran.

- Proses

Setelah ada data masukan, maka proses selanjutnya yaitu proses integrasi menggunakan API dari Google Classroom dimulai dari proses autentikasi akun. Setelah proses tersebut, akun dapat akses materi mata pelajaran, rekap absen serta nilai yang diperoleh selama pembelajaran.

- Output

Keluaran yang dihasilkan oleh sistem tersebut berupa laporan aktifitas pembelajaran guru dan siswa berupa rekap absensi dan rekap penilaian mata pelajaran.

c. Pembuatan Kode Program

Desain harus ditranslasikan kedalam program perangkat lunak. Hasil dari tahap ini adalah program komputer sesuai dengan desain yang telah dibuat pada tahap desain. Kode program ini berbasis website yang menggunakan bahasa pemrograman PHP.

d. Pengujian

Pengujian fokus pada perangkat lunak secara dari segi logika dan fungsional dan memastikan bahwa semua bagian sudah diuji. Hal ini dilakukan untuk meminimalisir kesalahan (error) dan memastikan keluaran yang dihasilkan sesuai dengan yang diinginkan. Pengujian sistem ini memakai metode black box testing.

e. Pemeliharaan (Maintenance)

Dalam tahap ini dilakukan pengembangan sistem seperti penambahan fitur dan fungsi baru. Akan tetapi, tahap Pemeliharaan (Maintenance) berada di luar lingkup penelitian atau tidak dikerjakan dalam penelitian ini.

\section{Dokumentasi}

Dokumentasi merupakan tahapan penting untuk suatu penelitian yang juga terdapat proses pembangunan sistem di dalamnya. Semua tahapan yang dilakukan dituangkan ke dalam sebuah tulisan, diagram, gambar, atau bentuk pemodelan yang lainnya guna mengetahui tahapan apa saja yang dilakukan untuk pembangunan perangkat lunak pada Sekolah Menengah Kejuruan Angkasa Husein Sastranegara Bandung.

\section{ANALISA DAN HASIL}

\section{a. Media Pembelajaran Classroom}

Dalam optimalisasi proses pembelajaran yang dapat dilakukan dengan mengintegrasi [3] dalam proses absensi [13] sesuai event [14]. Penggunaan google classroom sebagai media pembelajaran yang tepat dapat menjadikan proses belajar menjadi menarik dan menyenangkan serta dapat mengurangi kesalahfahaman. Pembelajaran yang dapat dilakukan dimana saja dan kapan saja secara langsung merupakan salah satu penggunaan teknologi. Hasil dari penelitian ini adalah multimedia pembelajaran interaktif yang dapat diterapkan pada kelas semu menggunakan Google Classroom dengan basis adobe Flash yang mampu 
dijangkau pembelajar serta media ini dapat digunakan oleh pembelajar maupun pengajar untuk lebih menarik pembelajar belajar elektronika [4].

\section{b. E-Learning}

E-Learning merupakan sistem informasi yang banyak digunakan dengan tujuan memberikan penghematan waktu, sumber daya dalam pelaksanaan kegiatan akademik [4]. E-Learning agar meningkatkan motivasi belajar [6] antara siswa dan guru [7][8][9] secara interaktif [10] tidak lagi terhalang oleh jarak, ruang dan waktu [11][12][13]. Penggunaan E-Learning dapat mempersingkat jadwal target waktu dan menghemat biaya [14] dalam sistem pembelajaran berbasis online [15]. Dengan adanya E-Learning sistem pendidikan yang responsif terhadap perubahan dan tuntutan zaman [8] dangan pembelajaran jarak jauh [16] dan siswa dapat mengupload tugas yang diberikan oleh guru [17]. E-Learning memiliki kelebihan antara lain : lebih mudah untuk diserap, jauh lebih efektif didalam biaya, jauh lebih ringkas, dan tersedia dalam 24 jam per hari [18].

\section{c. Unified Modeling Language}

Unified Modeling Language (UML) merupakan salah satu standar bahasa yang banyak digunakan di dunia industri untuk mendefinisikan requirement, membuat analisis dan desain, serta menggambarkan arsitektur dalam berorientasi objek. Pada diagram UML terbagi menjadi 3 katagori yaitu : structure diagrams, behavior diagrams, dan interaction diagrams[20]. Pada UML 2.3 terdiri dari 13 macam diagram dalam pembagian katagori diagram dapat dilihat pada gambar 3.

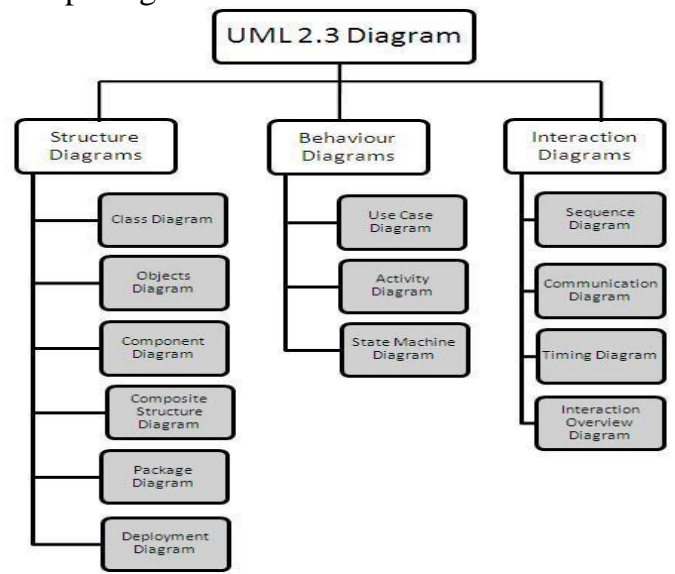

\section{d. Usecase Diagram}

Gambar 3. Diagram UML

Use Case Diagram menggambarkan fungsionalitas dari sebuah sistem, sebuah use case merepresentasikan sebuah interaksi antara aktor dengan sistem, aktor dapat berupa orang, peralatan atau sistem lain yang berinteraksi dengan sistem yang akan dibangun dan juga menggambarkan fungsionalitas sistem atau persyaratan - persyaratan yang harus dipenuhi sistem dari pandangan pengguna. Use Case Diagram Perangkat Lunak E-Learning dalam Kegiatan Belajar Mengajar di Sekolah Menengah Kejuruan Angkasa Husein dijelaskan pada Gambar 4. 


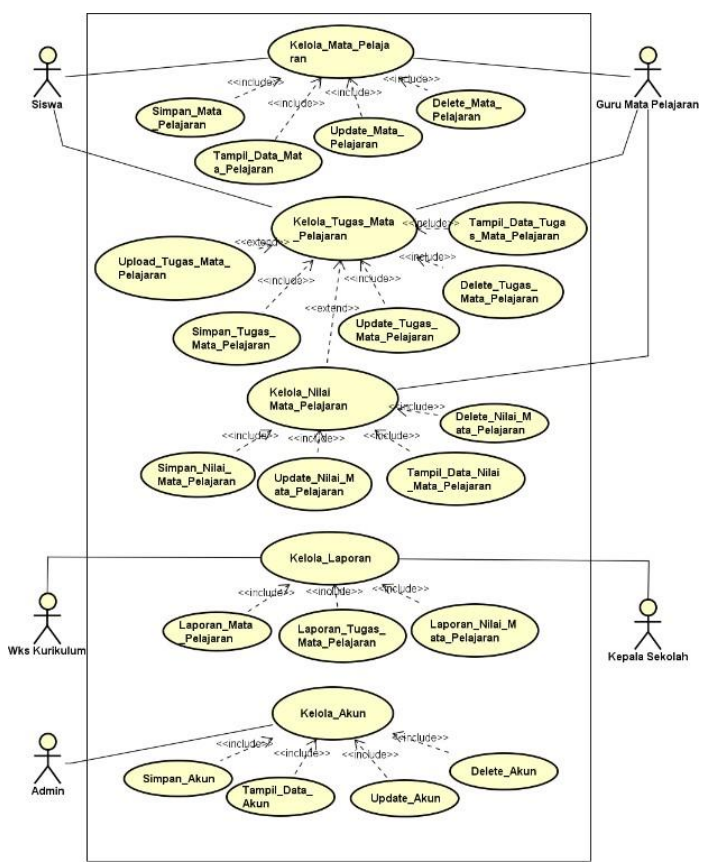

Gambar 4. Use Case Diagram

\section{e. Class Diagram}

Class Diagram merupakan suatu cara memetakan struktur sistem dengan memodelkan kelas, attribut, operasi serta hubungan antar objek. Class menggambarkan method atau atribut yang dikerjakan oleh sistem. Pada class diagram ini terdapat atribut dan method, atribut terbentuk dari analisis dokumen pada analisis dokumen sistem berjalan dan method yang terbentuk dari fungsi pada aktivitas sequence diagram dijelaskan pada gambar 5 .

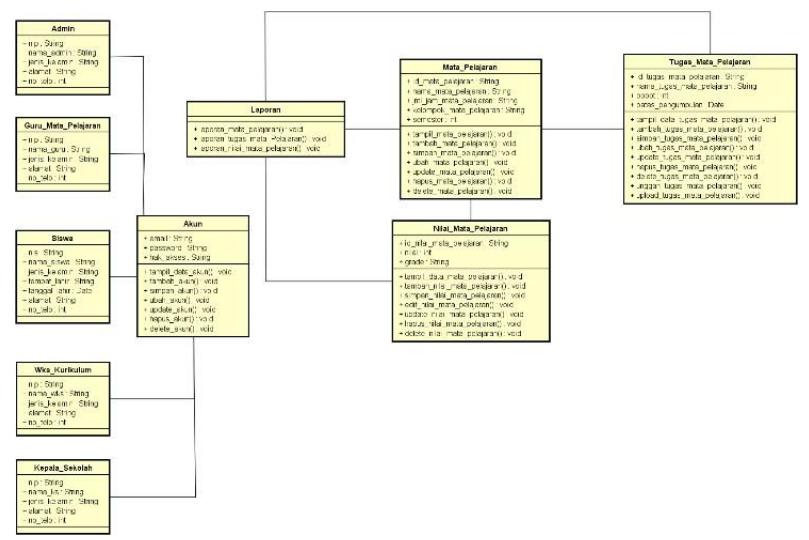

\section{f. Implementasi dan Pengujian}

Gambar 5. Class Diagram

Implementasi Antarmuka merupakan tampilan yang ada pada Pembangunan Perangkat Lunak E-Learning dalam Kegiatan Belajar Mengajar Sekolah Menengah Kejuruan Angkasa Husein. Implementasi Antarmuka terdiri dari implementasi antarmuka kelola mata pelajaran, implementasi antarmuka kelola tugas mata pelajaran, implementasi antarmuka kelola nilai mata pelajaran, implementasi antarmuka kelola laporan, dan implementasi antarmuka kelola akun.

a) Implementasi Antarmuka Kelola Mata Pelajaran 
Implementasi antarmuka kelola mata pelajaran menampilkan data mata pelajaran yang tersimpan pada database sistem. Implementasi antarmuka kelola mata pelajaran ditunjukkan pada Gambar 6.

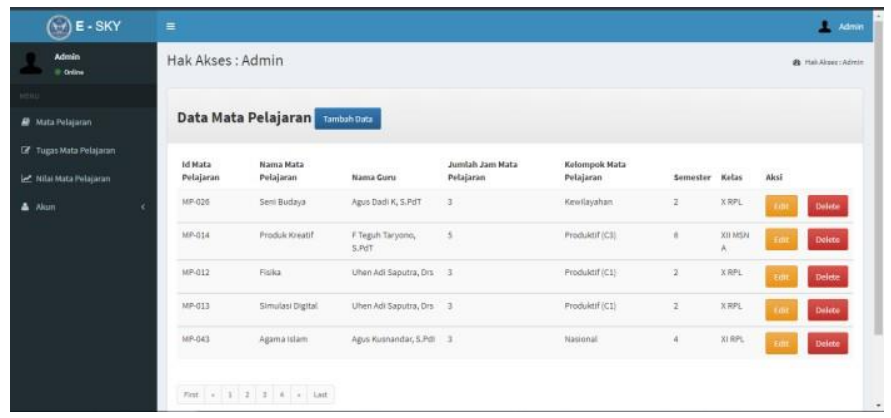

Gambar 6. Implementasi Antarmuka Kelola Mata Pelajaran

\section{b) Implementasi Antarmuka Kelola Tugas Mata Pelajaran}

Implementasi antarmuka kelola tugas mata pelajaran menampilkan data tugas mata pelajaran yang diberikan dari guru ke siswa. Implementasi antarmuka kelola tugas mata pelajaran ditunjukkan pada Gambar 7.

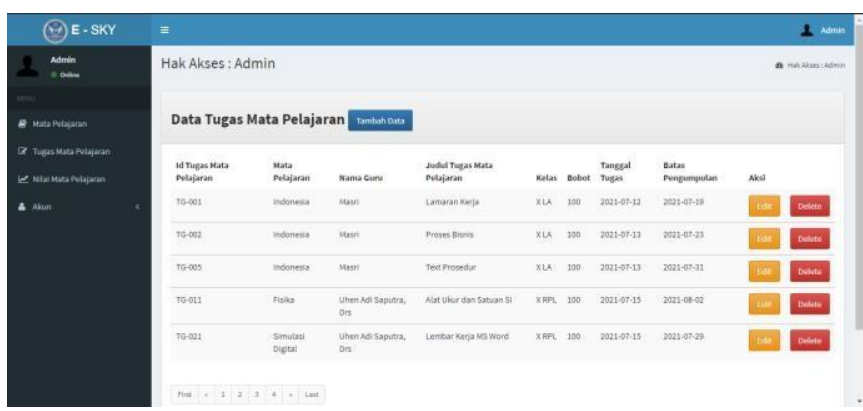

Gambar 7. Implementasi Antarmuka Kelola Tugas Mata Pelajaran

\section{c) Implementasi Antarmuka Kelola Nilai Mata Pelajaran}

Implementasi antarmuka kelola nilai mata pelajaran menampilkan data nilai yang diterima siswa dari guru mata pelajaran. Implementasi antarmuka kelola nilai mata pelajaran ditunjukkan pada Gambar 8 .

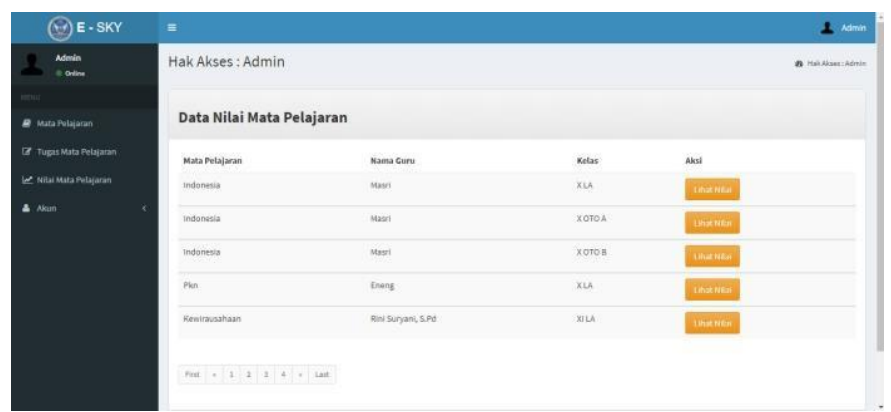

Gambar 8. Implementasi Antarmuka Nilai Mata Pelajaran

d) Implementasi Antarmuka Kelola Akun 
Implementasi antarmuka kelola akun terdiri dari data akun admin, akun guru, akun wks kurikulum, akun kepala sekolah, siswa.

\section{- Admin}

Implementasi untuk akun admin menampilkan data akun admin sebagai hak akses.

Implementasi akun admin ditunjukkan pada Gambar 9.

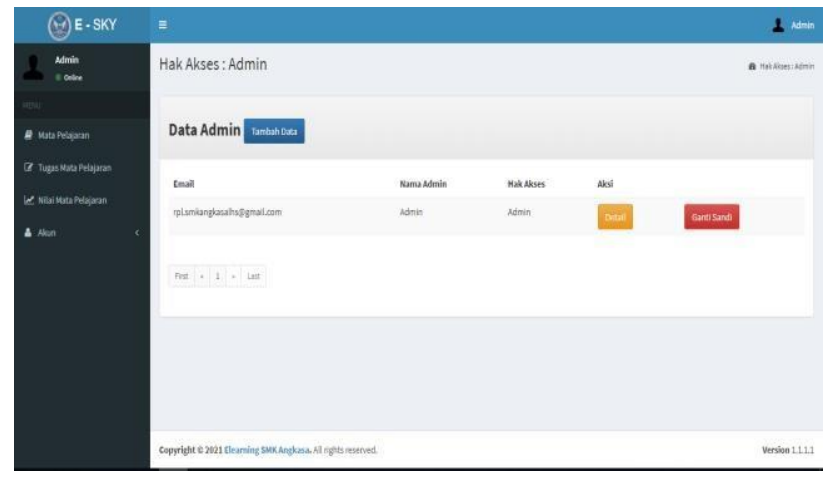

Gambar 9. Implementasi Antarmuka Kelola Akun Admin

\section{- Guru}

Implementasi untuk akun guru menampilkan data akun guru sebagai hak akses.

Implementasi akun guru ditunjukkan pada Gambar 10.

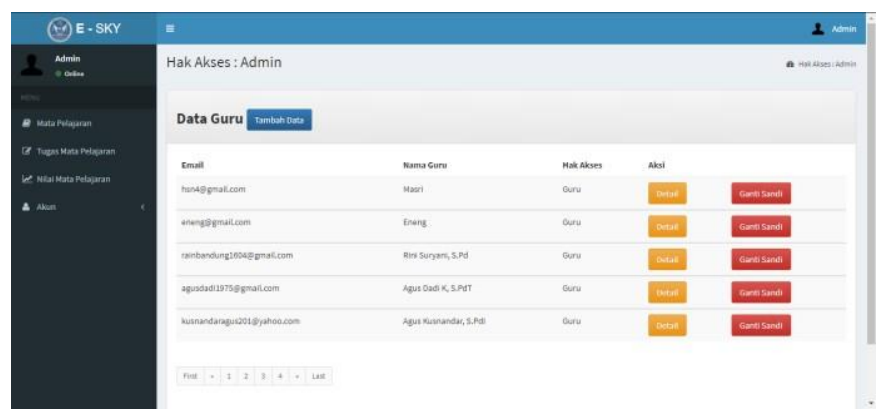

Gambar 10. Implementasi Antarmuka Kelola Akun Guru

\section{- Wks Kurikulum}

Implementasi untuk akun wks kurikulum menampilkan data akun wks kurikulum sebagai hak akses. Implementasi akun wks kurikulum ditunjukkan pada Gambar 11.

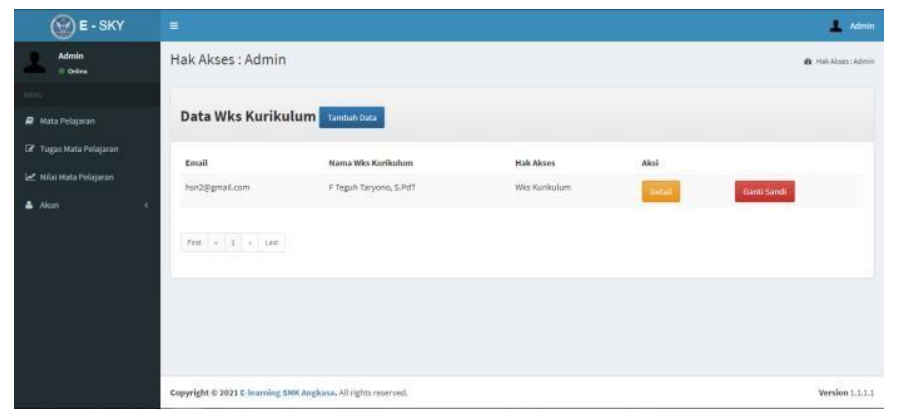

Gambar 11. Implementasi Antarmuka Kelola Akun Wks Kurikulum

\section{- Kepala Sekolah}

Implementasi untuk akun kepala sekolah menampilkan data akun kepala sekolah sebagai hak akses. Implementasi akun kepala sekolah ditunjukkan pada Gambar 12. 


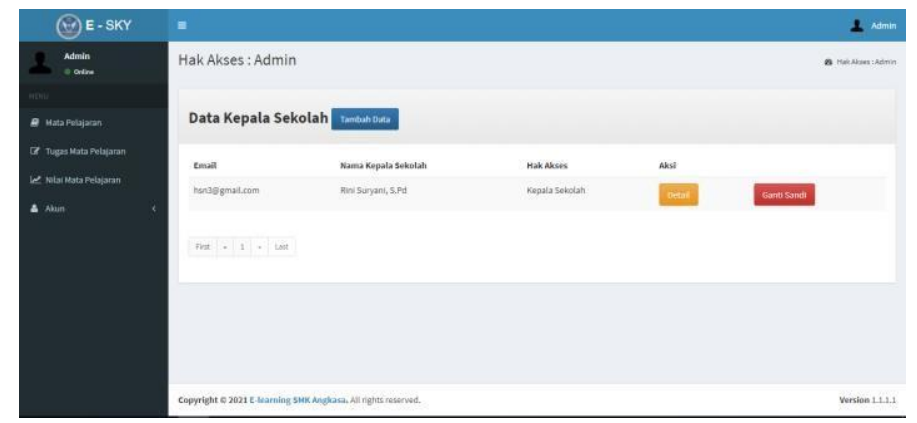

Gambar 12. Implementasi Antarmuka Kelola Akun Kepala Sekolah

\section{- Siswa}

Implementasi untuk akun siswa menampilkan data akun siswa sebagai hak akses.

Implementasi akun siswa ditunjukkan pada Gambar 13.

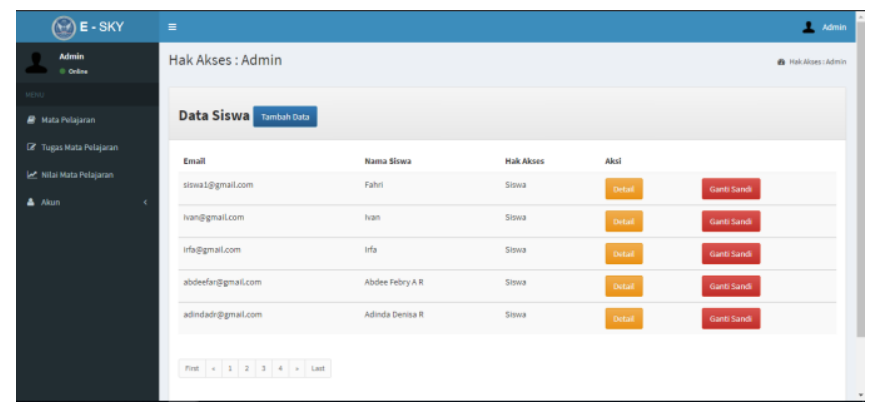

Gambar 13. Implementasi Antarmuka Kelola Akun Siswa

\section{KESIMPULAN}

\section{a. Kesimpulan}

Berdasarkan penelitian yang telah dilakukan, dapat disimpulkan beberapa hal yaitu :

- Platform Google Classroom dapat dimodifikasikan sesuai kebutuhan sekolah yang dapat membantu manajemen sekolah baik sisi Guru Mata Pelajaran hingga Siswa untuk standar ketercapaian kurikulum sekolah. Dengan penggunaan E-Learning dapat membuat perangkat lunak dapat berbagi informasi dari menajemen sekolah untuk monitoring proses belajar mengajar Guru Mata Pelajaran dan Siswa.

\section{b. Saran}

Berdasarkan penelitian yang telah dilakukan, dapat disarankan untuk penelitian selanjutnya yaitu :

- Perangkat lunak dapat dikembangkan menggunakan mobile.

- Dapat menambahkan fitur absensi dengan integrasi lokasi terkini agar pihak sekolah dapat mengetahui posisi lokasi siswa.

- Dapat menambahkan fitur streaming video conference antara guru mata pelajaran dan siswa.

\section{REFERENSI}

[1] D. P. Sari, R. A. Sukmawati, H. S. Purba, D. M. Muhammad, and S. H. Azis, "Pelatihan Penggunaan Google Classroom untuk Mengoptimalkan Proses Pembelajaran," Bubungan Tinggi J. Pengabdi. Masy., vol. 1, no. 2, p. 56, 2020, doi: 10.20527/btjpm.v1i2.1785.

[2] M. H. Wijaya, M. Sarosa, and H. Tolle, "Rancang Bangun Chatbot Pembelajaran Java pada Google Classroom dan Facebook Messenger," J. Teknol. Inf. dan Ilmu Komput., vol. 5, no. 3, p. 287, 2018, doi: 10.25126/jtiik.201853837.

[3] U. Rahardja, Q. Aini, and N. P. L. Santoso, "Pengintegrasian YII Framework Berbasis API pada Sistem Penilaian Absensi," Sisfotenika, vol. 8, no. 2, p. 140, 2018, doi: 10.30700/jst.v8i2.403. 
[4] A. Setiawan, L. Nurlaela, S. Muslim, E. Yundra, and P. Studi Pendidikan Vokasi Universitas Negeri Surabaya Jalan Lidah Wetan Surabaya, "Pengembangan E Learning Sebagai Media Pembelajaran Pendidikan Vokasi," no. September, pp. 52-56, 2019.

[5] W. Hidayat and N. A. Sudibyo, "Implementasi Pembelajaran Interaktif Elektronika Dasar Menggunakan Adobe Flash CS6 Pada Kelas Semu dengan Google Classroom Berbasis Framework RAD," Sains dan Edukasi Sains, vol. 1, no. 2, pp. 17-24, 2018.

[6] I. W. K. Suwastika, "Pengaruh E-Learning sebagai Salah Satu Media Pembelajaran Berbasis Teknologi Informasi Terhadap Motivasi Belajar Mahasiswa,” J. Sist. dan Inform., vol. 13, no. 1, pp. 1-5, 2018, [Online]. Available: https://jsi.stikom-bali.ac.id/index.php/jsi/article/view/185.

[7] H. T. SIHOTANG, "Pembuatan Aplikasi E-Learning Pada Smk Swasta Pariwisata Imelda Medan,” vol. 1, no. 2, pp. 70-75, 2019, doi: 10.31227/osf.io/dp6bz.

[8] D. Febriannisa and L. P. Hasugian, "Perancangan E-learning pada SMK Negeri 1 Bandung," J. Ultim. InfoSys, vol. 8, no. 2, pp. 62-68, 2018, doi: 10.31937/si.v8i2.613.

[9] S. Kosasi, "Perancangan E-learning untuk Meningkatkan Motivasi Belajar Guru dan Siswa," J. Inform., no. 0362, p. 27213, 2015, [Online]. Available: http://pti.undiksha.ac.id/senapati.

[10] R. S. Teuku Fadjar Shadek, "Pengembangan Aplikasi Sistem E-Learning Pada Seluruh Mata Kuliah Dengan Menggunakan Program Hypertext Prepocessor ( PHP ) Dalam Rangka Peningkatan Mutu Proses Dan Hasil Pembelajaran," J. ProTekInfo, vol. 4, pp. 1-18, 2017.

[11] W. Muna and L. Hadisi, "Pengelolaan Teknologi Informasi Dalam Menciptakan Model Inovasi Pembelajaran (Elearning)," J. Al-Ta'dib, vol. 8, no. 1, pp. 1-24, 2015.

[12] J. C. Wibawa and E. Edah, “Aplikasi E-Learning Di SMP Negeri 46 Bandung,” J. Teknol. dan Inf., vol. 5, no. 1, pp. 1-10, 2015.

[13] B. Dina Maulina, "Perancangan Sistem Informasi E-Learning Pada SMK Syubbanul Wathon Tegalrejo Magelang,” J. Ilm. DASI, vol. 18 No. 1, pp. 8-13, 2017.

[14] Sudarmaji, "Migrasi dan Optimalisasi Database Sistem Informasi berbasis E-Learning Program Diploma III Manajemen Informatika Universitas Muhammadiyah Metro," MIKROTIK J. Manaj. Inform., vol. 6, no. 2, p. 8, 2016, [Online]. Available: https://ojs.ummetro.ac.id/index.php/mikrotik/article/view/440.

[15] Y. Irawan, N. Susanti, and W. A. Triyanto, "Analisa Dan Perancangan Sistem Pembelajaran Online (E-Learning) Pada Smk Mambaul Falah Kudus,” Simetris J. Tek. Mesin, Elektro dan Ilmu Komput., vol. 6, no. 2, p. 345, 2015, doi: 10.24176/simet.v6i2.471.

[16] A. Cucus and Y. Aprilinda, "Pengembangan E-Learning Berbasis Multimedia untuk Efektivitas Pembelajaran Jarak Jauh,” Explor. J. Sist. Inf. dan Telemat., vol. 7, no. 1, pp. 1-5, 2016, doi: 10.36448/jsit.v7i1.765.

[17] E. Supratman and F. Purwaningtias, "Pengembangan Media Pembelajaran E-Learning Berbasis Schoology," $J$. Inform. J. Pengemb. IT, vol. 3, no. 3, pp. 310-315, 2018, doi: 10.30591/jpit.v3i3.958.

[18] Kuryanti and J. K. Sandra, "Rancang Bangun Sistem E-Learning sebagai Sarana Pemberlajaran,” J. Khatulistiwa Inform., vol. 4, no. 1, pp. 84-92, 2016, doi: 10.1089/pho.2010.2784. 